Case Report

\title{
Homozygosity for the E526V Mutation in Fibrinogen A Alpha-Chain Amyloidosis: The First Report
}

\author{
Isabel Tavares, ${ }^{1,2}$ Luísa Lobato, ${ }^{3,4}$ Carlos Matos, ${ }^{3}$ Josefina Santos, ${ }^{3,4}$ \\ Paul Moreira, ${ }^{5}$ Maria João Saraiva, ${ }^{5}$ and António Castro Henriques ${ }^{3,4}$ \\ ${ }^{1}$ Department of Nephrology, Centro Hospitalar de São João, 4200-319 Porto, Portugal \\ ${ }^{2}$ Nephrology and Infectious Diseases Research and Development Group, INEB (I3S), University of Porto, 4150-180 Porto, Portugal \\ ${ }^{3}$ Department of Nephrology, Centro Hospitalar do Porto, Hospital de Santo António, 4099-001 Porto, Portugal \\ ${ }^{4}$ Unit for Multidisciplinary Research in Biomedicine, Instituto de Ciências Biomédicas Abel Salazar, University of Porto, \\ 4050-313 Porto, Portugal \\ ${ }^{5}$ Molecular Neurobiology, Institute of Molecular and Cellular Biology, University of Porto, 4150-180 Porto, Portugal
}

Correspondence should be addressed to Isabel Tavares; isabel.salome@hsjoao.min-saude.pt

Received 29 March 2015; Accepted 9 June 2015

Academic Editor: Raoul Bergner

Copyright (C) 2015 Isabel Tavares et al. This is an open access article distributed under the Creative Commons Attribution License, which permits unrestricted use, distribution, and reproduction in any medium, provided the original work is properly cited.

\begin{abstract}
Systemic hereditary amyloidoses are autosomal dominant diseases associated with mutations in genes encoding ten different proteins. The clinical phenotype has implications on therapeutic approach, but it is commonly variable and largely dependent on the type of mutation. Except for rare cases involving gelsolin or transthyretin, patients are heterozygous for the amyloidogenic variants. Here we describe the first patient identified worldwide as homozygous for a nephropathic amyloidosis, involving the fibrinogen variant associated with the fibrinogen alpha-chain E526V (p.Glu545Val) mutation. In 1989, a 44-year-old woman presented with hypertension, hepatosplenomegaly, nephrotic syndrome, and renal failure. She started hemodialysis in 1990 and 6 years later underwent isolated kidney transplantation from a deceased donor. Graft function and clinical status were unremarkable for 16 years, despite progressively increased left ventricular mass on echocardiography. In 2012, 4 months before death, she deteriorated rapidly with severe heart failure, precipitated by Clostridium difficile colitis and urosepsis. Affected family members developed nephropathy, on average, nearly three decades later, which may be explained by the gene dosage effects on the phenotype of E526V (p.Glu545Val) fibrinogen A alpha-chain amyloidosis.
\end{abstract}

\section{Introduction}

Hereditary fibrinogen A alpha-chain (AFib) amyloidosis is a systemic amyloid disease first characterized in 1993 in a Peruvian kindred [1-4]. It presents with proteinuria and features a progressive decline in kidney function to end stage renal failure (ESRF) within 5 years of diagnosis [3]. Nonetheless, there is a wide variability in disease onset, systemic involvement, and penetrance. Renal replacement therapy and transplantation are currently the mainstay of therapy. However, because the liver is the source of the amyloidogenic variant fibrinogen and there is no evidence that WT fibrinogen can be amyloidogenic, the only curative treatment is liver transplantation [5].
AFib amyloidosis appears to be more common worldwide than previously recognized [6]. The R554L (p.Arg573Leu) mutation was the first fibrinogen amyloidogenic variant identified [1]. To date, thirteen amyloidogenic mutations have been reported in the fibrinogen alpha-chain gene (FGA) (http://amyloidosismutations.com/mut-afib.php), accounting for $8 \%$ of hereditary amyloidosis cases [7]. The most common mutant variant, E526V (p.Glu545Val), was identified heterozygously in kindred members of Irish, British, Polish, Portuguese, French, German, and Brazilian origin [2, 3, 811]. Homozygosity has only been reported for hereditary gelsolin and transthyretin amyloidosis (Table 1). In gelsolin (AGel) amyloidosis, homozygotes have been reported to show earlier onset and more severe clinical manifestations 
TABLE 1: Homozygous amyloidogenic variants reported in the literature.

\begin{tabular}{|c|c|c|c|c|c|c|c|}
\hline Gene & $\begin{array}{l}\text { Protein } \\
\text { variant }\end{array}$ & $\begin{array}{c}\text { Sequence } \\
\text { variant (mRNA) }\end{array}$ & Patients $(n)$ & $\begin{array}{c}\text { Geographic } \\
\text { origin/ethnicity }\end{array}$ & $\begin{array}{l}\text { Reported } \\
\text { phenotype }\end{array}$ & Clinical course & References \\
\hline GSN & $\begin{array}{c}\text { Asp187Asn } \\
\text { (p.Asp214Asn) }\end{array}$ & c. $640 \mathrm{G}>\mathrm{A}$ & 2 & Finland & $\begin{array}{c}\mathrm{CN}, \mathrm{CLD}, \mathrm{SC}, \\
\mathrm{CRF}\end{array}$ & Severe nephropathy & {$[12,13]$} \\
\hline$T T R$ & $\begin{array}{c}\text { Val30Met } \\
\text { (p.Val50Met) }\end{array}$ & c. $148 \mathrm{G}>\mathrm{A}$ & 19 & $\begin{array}{l}\text { Japan } \\
\text { Spain } \\
\text { Sweden } \\
\text { Turkey }\end{array}$ & $\begin{array}{l}\mathrm{PN}, \mathrm{AN}, \mathrm{VO} \\
\text { GI, } \mathrm{H}, \mathrm{CN}\end{array}$ & $\begin{array}{l}\text { Wide variability, from } \\
\text { asymptomatic carriers to slightly } \\
\text { more severe phenotypes with } \\
\text { higher incidence rate and earlier } \\
\text { onset than heterozygotes within } \\
\text { the same family }\end{array}$ & [14-19] \\
\hline & $\begin{array}{c}\text { Leu58His } \\
\text { (p.Leu78His) }\end{array}$ & c. $233 \mathrm{~T}>\mathrm{G}$ & 1 & American/German & PN, CMP & More rapid course of disease & {$[20]$} \\
\hline & $\begin{array}{c}\text { Phe64Leu } \\
\text { (p.Phe84Leu) }\end{array}$ & c. $250 \mathrm{~T}>\mathrm{C}$ & 1 & Italy & $\begin{array}{c}\mathrm{PN}, \mathrm{AN}, \\
\mathrm{CMP}\end{array}$ & More severe phenotype & [21] \\
\hline & $\begin{array}{l}\text { Val122Ile } \\
\text { (p.Val142Ile) }\end{array}$ & c. $424 \mathrm{G}>\mathrm{A}$ & 24 & African/American & CMP & $\begin{array}{l}\text { Earlier age at onset and uncertain } \\
\text { penetrance, particularly with } \\
\text { respect to gender }\end{array}$ & {$[22,23]$} \\
\hline
\end{tabular}

AN: autonomic neuropathy; CLD: corneal lattice dystrophy; CMP: cardiomyopathy; CN: cranial neuropathy; CRF: chronic renal failure; GI: gastrointestinal symptoms; H: heart conduction disturbance; PN: peripheral polyneuropathy; SC: skin changes; VO: vitreous opacities.

than heterozygotes, explained by the lethal effects of the mutant genes [12, 13]. However, in transthyretin (ATTR) amyloidosis, the underlying molecular mechanisms are largely unknown [14-23].

Here, we report the first homozygous patient with AFibE526V (p.Glu545Val) amyloidosis, identified in 1989 and followed up for 23 years. In this reported kindred, the comparison of the clinical pictures of homozygote and heterozygotes provides important information about the gene dosage effects on the phenotype of AFib amyloidosis.

\section{Case Report}

2.1. Proband. A 44-year-old Caucasian northern Portuguese woman who had suffered a single previous episode of upper gastrointestinal hemorrhage presented with hypertension, nephrotic syndrome, and renal failure in April 1989. Renal biopsy 1 year later revealed abundant glomerular amyloid deposition (Figure 1(a)); her serum creatinine was $4.0 \mathrm{mg} / \mathrm{dL}$ and proteinuria of $7.5 \mathrm{~g} /$ day was detected. In the absence of any underlying inflammatory disease and unawareness of family history, she was presumed to have immunoglobulin light chain (AL) amyloidosis. However, there was no evidence of cardiac amyloidosis, and neither a monoclonal immunoglobulin nor a plasma cell disorder was identified. She was treated with melphalan and corticosteroids but progressed rapidly to ESRF and started hemodialysis in December 1990. During hemodialysis, her functional status remained good.

Successful isolated renal transplantation (RTx) was performed in August 1996. At the time, she had no other health problems. Physical examination revealed an enlarged liver and spleen. There was no anemia or thrombocytopenia and liver function tests were normal. Blood coagulation tests revealed low fibrinogen levels. Echocardiography showed mild left ventricular hypertrophy without the typical speckle appearance. Abdominal ultrasonography showed hepatomegaly $(17.5 \mathrm{~cm})$, splenomegaly $(14.5 \mathrm{~cm})$, and bilateral kidney atrophy. A neurophysiologic study of the lower limbs found mild sensory peripheral neuropathy. Induction and maintenance immunosuppression for transplantation involved corticosteroids, cyclosporine, and azathioprine.

2.2. Histology and Immunohistochemistry. In 2001, we began an extensive investigation to determine the patient's amyloid type. Congo red staining of $6 \mu \mathrm{m}$ formalin fixed, paraffin embedded section of the native kidney biopsy confirmed abundant glomerular amyloid deposition and absence of vascular and interstitial involvement. Immunohistochemical staining was performed on $2 \mu \mathrm{m}$ sections of amyloid-containing tissue using standard methods and a rabbit/mouse, peroxidase/diaminobenzidine detection system (REAL EnVision: Dako, Glostrup, Denmark). mAbs were directed against serum amyloid A (Dako), apolipoprotein AII (Abcam, Cambridge, UK), and transthyretin [24]; polyclonal antibodies were used for kappa light chain, lambda light chain, fibrinogen A alpha-chain (FGA), transthyretin, apolipoprotein A-I, and lysozyme (Dako). For light chains and FGA, sections were treated with $10 \mu \mathrm{g} / \mathrm{mL}$ proteinase $\mathrm{K}$ for $10 \mathrm{~min}$ at $37^{\circ} \mathrm{C}$ and $10 \mathrm{~min}$ at room temperature. Blocking was performed with $5 \%$ bovine serum albumin/phosphate buffered saline (BSA/PBS). Sections were incubated with the antibodies for $2 \mathrm{~h}$ at room temperature and diluted in 1\% BSA/PBS as follows: monoclonal anti-transthyretin, used directly; polyclonal anti-transthyretin, 1:500; anti-serum amyloid A, 1:100; anti-kappa light chain, 1:1000; anti-lambda light chain, 1:2000; anti-FGA, 1:800; anti-lysozyme, 1:300; anti-apolipoprotein A-I, 1:400; and anti-apolipoprotein AII, 1:600. Positive control tissues containing these amyloid proteins were also stained during each run. The glomerular amyloid deposits in the patient's kidney biopsy reacted with the anti-serum to FGA (Figure 1(a)). 

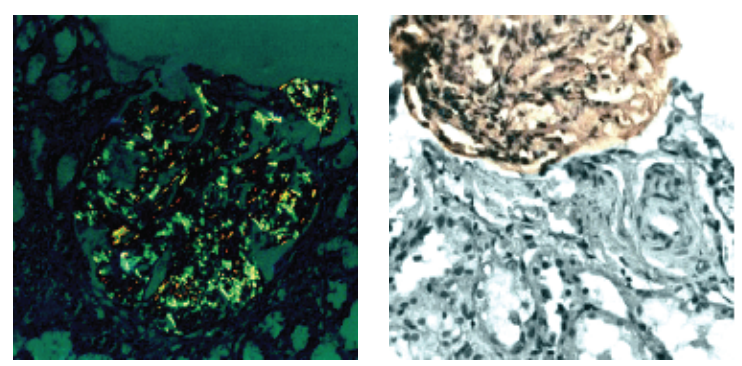

(a)

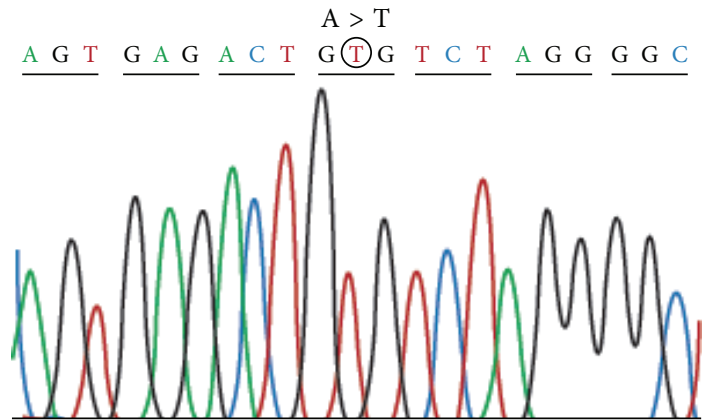

(b)

(I)

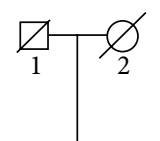

(II)

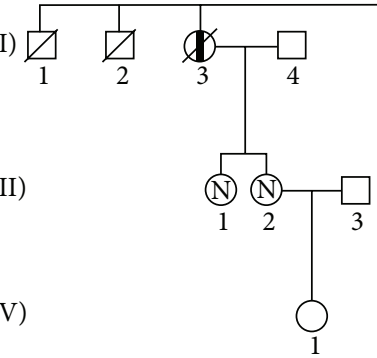

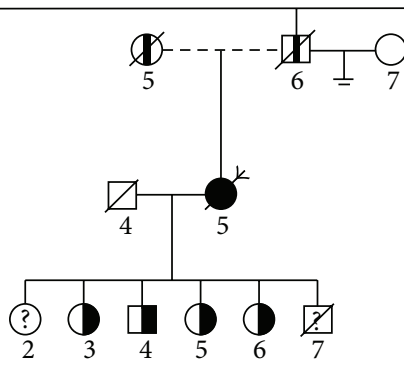

(c)

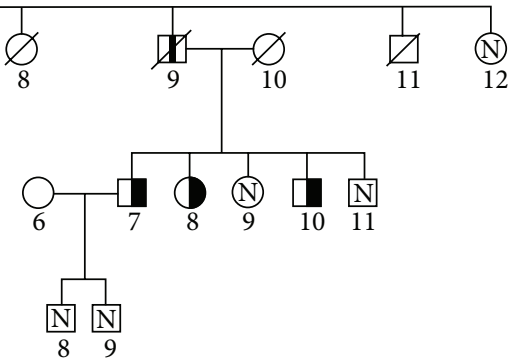

Figure 1: Homozygous E526V (p.Glu545Val) mutation in the fibrinogen alpha-chain gene (FGA) associated with fibrinogen A alpha-chain amyloidosis in a Portuguese patient. (a) shows abundant glomerular amyloid deposition with typical apple-green birefringence (Congo red staining under polarized light, $\times 200$, left). Immunohistochemical staining was positive with polyclonal anti-fibrinogen antibodies, $(\times 200$, right). (b) shows a partial sequence chromatogram of FGA. The mutation identified in the proband, which alters codon 545 (position 526 of the mature protein) from GAG (glutamic acid) to GTG (valine), is depicted in a circle. (c) shows the pedigree of the affected kindred. The homozygous patient (proband) is indicated by the arrow. The FGA p.Glu545Val mutation was identified heterozygously in family members III7, III8, III10, IV3, IV4, IV5, and IV6 (indicated by half-solid symbols). Obligatory heterozygotes IV2 and IV7 (indicated by question marks) did not perform genotyping because the former was abroad and the latter died at young age. Those with chronic renal failure who have not undergone histologic or genetic testing are indicated by a black column inside the symbol. Familiars whose genetic tests were negative are indicated by an $\mathrm{N}$ inside the symbol. Blank symbols indicate that tests have not been conducted and/or information is unavailable for these individuals. Slashes denote deceased members.

2.3. Genetic Evaluation. DNA was extracted from peripheral white blood cells obtained from whole blood. Exon 5 of the FGA gene was amplified by the polymerase chain reaction (PCR) with primers flanking the coding region (forward $5^{\prime}$ CCT TCT TCG ACA CTG CCT CAA CTG- $3^{\prime}$ and reverse $5^{\prime}$-TCC TCT GTT GTA ACT CGT GCT-3'), which amplified a fragment of 224 base pairs encompassing nucleotide 4827 to 5051 . PCR products were analyzed by agarose gel electrophoresis, purified, and sequenced with Big Dye Terminator Cycle Sequencing Kit (Applied Biosystems, Foster City, CA, USA) in an Applied Biosystems 3700 sequencer. Sequences were analysed using ChromasPro. A homozygous A to $\mathrm{T}$ transversion at nucleotide 4909 in FGA was detected; this changes codon 526 of the mature protein (corresponding to position 545 of the unprocessed gene product), from GAG, encoding glutamic acid, to GTG, encoding valine (Figure 1(b)). Codons are numbered according to reference sequence NM_000508.3.
2.4. Proband Outcome. During 16 years of follow-up after RTx, there were no episodes of rejection and she was normotensive. Maximal proteinuria of $0.9 \mathrm{~g} /$ day was detected in 2009 and renal graft function remained good until 4 months before her death; thus, no renal allograft biopsy was performed. Peptic ulcer due to Helicobacter pylori infection was diagnosed after an episode of upper gastrointestinal hemorrhage. Apparent progression of extrarenal amyloid disease was mainly cardiovascular and hepatic. Repeated electrocardiography found sinus rhythm, normal intervals, and no criteria for hypertrophy. Serial echocardiography showed left atrial enlargement $(53 \mathrm{~mm})$, severely abnormal left ventricular hypertrophy (left ventricular mass index increased from $154 \mathrm{~g} / \mathrm{m}^{2}$ in 2006 to $170 \mathrm{~g} / \mathrm{m}^{2}$ in 2012 , with a reference range of $43-95 \mathrm{~g} / \mathrm{m}^{2}$ ), mild degenerative valvular disease, preserved systolic ventricular function, and moderate pulmonary hypertension. These findings were consistent with cardiac amyloidosis. Hepatic involvement was characterized by mild elevations of gamma-glutamyl transferase 
TABLE 2: Laboratory data.

\begin{tabular}{|c|c|c|c|c|c|c|}
\hline Parameter/date & 02.14 .2006 & 04.07 .2009 & 08.17 .2010 & 08.14 .2012 & 11.26 .2012 & 12.05 .2012 \\
\hline Urea (mg/dL) & 69 & 41 & 89 & 136 & 135 & 188 \\
\hline Creatinine (mg/dL) & 0.80 & 0.75 & 1.03 & 1.22 & 1.44 & 4.62 \\
\hline Creatinine clearance $\left(\mathrm{mL} / \mathrm{min} / 1.73 \mathrm{~m}^{2}\right)$ & 67.9 & 84.7 & 68.3 & 45.9 & 37.6 & 9.2 \\
\hline Albumin (g/L) & 43.0 & & 45.7 & & & \\
\hline HbAlc (\%) & & & 5.9 & & & \\
\hline Uric acid (mg/dL) & & 6.7 & 8.9 & 7.0 & & \\
\hline Total bilirubin (mg/dL) & 0.79 & 0.60 & 0.60 & 0.72 & 1.13 & 0.96 \\
\hline AST (U/L) & 21 & 23 & 23 & 19 & 14 & 22 \\
\hline $\operatorname{ALT}(\mathrm{U} / \mathrm{L})$ & 19 & 14 & 20 & 15 & 2 & 12 \\
\hline $\operatorname{ALP}(\mathrm{U} / \mathrm{L})$ & 102 & 106 & 134 & 139 & 160 & 170 \\
\hline GGT (U/L) & 90 & 86 & 88 & 81 & 106 & 65 \\
\hline Sodium (mmol/L) & 144 & & 134 & 136 & 132 & 122 \\
\hline Potassium (mmol/L) & 4.73 & & 4.17 & 4.50 & 4.87 & 5.73 \\
\hline Chloride (mmol/L) & 106 & & 96 & 101 & 96 & 98 \\
\hline Calcium $(\mathrm{mmol} / \mathrm{L})$ & 2.52 & & 2.56 & & & 2.02 \\
\hline Phosphorus (mmol/L) & 1.03 & & 1.18 & & & 2.09 \\
\hline iPTH (pg/mL) & 75 & 80 & 103 & & & \\
\hline Total cholesterol (mg/dL) & 203 & 207 & 196 & 155 & & \\
\hline Triglycerides (mg/dL) & 127 & 78 & 105 & 111 & & \\
\hline NT-proBNP (pg/mL) & & & & & 14056 & \\
\hline CRP (mg/dL) & & & & & & 85.62 \\
\hline Cyclosporine (ng/mL) & & 80.5 & 94.7 & & & 130.2 \\
\hline Proteinuria (g/24 h) & 0.15 & 0.90 & 0.51 & & & \\
\hline
\end{tabular}

HbAlc: glycated hemoglobin; AST: aspartate aminotransferase; ALT: alanine aminotransferase; ALP: alkaline phosphatase; GGT: gamma-glutamyl transferase; iPTH: intact parathyroid hormone; NT-proBNP: N-terminal pro-B-type natriuretic peptide; CRP: C-reactive protein.

and alkaline phosphatase with increasing hepatomegaly; the liver's ultrasound diameter reached $22.7 \mathrm{~cm}$ in September 2012. At that time, the spleen diameter was $9.4 \mathrm{~cm}$ and there were several calcifications. There was no sign of portal hypertension. Relevant laboratory data are listed in Table 2.

In August 2012, 4 months before her death, the patient was hospitalized for Clostridium difficile colitis, which was successfully treated with metronidazole. One month later, she was admitted for congestive heart failure with an $\mathrm{N}$ terminal pro-B-type natriuretic peptide (NT-proBNP) level of $31937 \mathrm{pg} / \mathrm{mL}$; this was controlled with diuretic therapy. In November 2012, she was hospitalized for hyponatremia associated with effective circulating volume depletion. She died in December 2012 after admission for Klebsiella pneumoniae urosepsis, congestive heart failure with NT-proBNP 14 $056 \mathrm{pg} / \mathrm{mL}$ unresponsive to diuretic therapy, and acute kidney allograft injury. Autopsy was not performed.

2.5. Kindred. After some years of research, a family tree was obtained (Figure 1(c)). The research protocol was approved by the Health Ethics Commission of Centro Hospitalar de São João. The mother of the proband (II5) presented with hypertension aged 67 years. She had a stroke at 76 years and died from chronic renal failure (CRF) 1 year later. The father (II6) had hypertension from the age of 55 years, significant cardiovascular disease (peripheral artery disease, ischemic cardiopathy), and CRF from 77 years, dying from pneumonia at 82 years. One paternal aunt (II3) died at 84 years due to hemorrhagic cerebrovascular accident. She had hypertension from the age of 59 years and CRF from 69 years and had started hemodialysis at 79 years. One paternal uncle (II9) had hypertension from the age of 61 years, significant cardiovascular disease (peripheral artery disease, ischemic cardiopathy), and CRF from 72 years, dying from uremia at 78 years. Three first cousins (III7, III8, and III10) had hypertension (from 57, 55, and 53 years, resp.) and carried the same amyloidogenic fibrinogen mutation. As patient III5 was homozygous for the FGA p.Glu545Val mutation, all her offspring are obligatory heterozygotes. This condition was confirmed by genotyping in all, except IV2, who was abroad, and IV7, who died at young age. Members IV3 and IV4 had hypertension from the age of 45 and 43 years, respectively.

\section{Discussion}

Here, we describe the first AFib amyloidosis patient homozygous for the E526V (p.Glu545Val) mutation and her long term outcome after isolated RTx. The unexpected etiology and outcome of this case highlight important aspects of the clinical management of systemic amyloidosis in general. Our patient's prolonged survival without treatment and the absence of an identifiable monoclonal plasma cell disorder led us to question the diagnosis of AL amyloidosis. Retrospective finding that the amyloid deposits in her kidney biopsy 
were derived from FGA and the complete concordance between the presence of the E526V (p.Glu545Val) and the development of amyloidosis indicated that this mutation was the cause of the disease in the proband's family. This approach ensured family screening.

Immunohistochemical classification of 102 northern Portuguese patients with amyloidosis diagnosed in native kidney biopsies disclosed 4 (3.9\%) cases of AFib, including our proband. They were all from the same rural geographical area and belonged to apparently unrelated families [25]. In the case of our homozygous patient, both parents had CRF and consanguinity was not possible to prove, but they may share a common ancestor given the possibility of an endemic focus of the disease in their region. In this context, homozygosity proposal was based on DNA sequencing (Figure 1(b)).

Previously reported AFib amyloidosis phenotypes result from the heterozygous genotype. The effect of homozygosity on phenotype has been reported for patients with hereditary transthyretin [14-23] or gelsolin [12,13] amyloidosis (Table 1), but this is the first report for AFib amyloidosis. Our patient presented at a relatively early age and during long term follow-up apparently developed a heavy disease burden with multisystem involvement. After RTx, serial echocardiography demonstrated increased wall thickness, despite normotension and normal graft function, consistent with cardiac amyloidosis. The main forms of amyloidosis that affect the heart are light chain and ATTR amyloidosis. Cardiac involvement of AFib amyloidosis was described in a cohort of $22 \mathrm{AFib}$ patients [4], 52\% had abnormal echocardiographic findings suggestive of amyloid cardiomyopathy, and 55\% had parasympathetic dysfunction and risk of bradycardia. Coronary atherosclerosis was identified in $68 \%$. In the present case, cardiac involvement in the setting of established AFib amyloidosis, with left ventricular hypertrophy on echocardiography and a relative low-voltage electrocardiogram, complicated by congestive heart failure refractory to standard medical therapy, was considered cardiac amyloidosis. Two of the family members developed atherosclerotic cardiovascular disease with no echocardiographic evidence of cardiac amyloidosis. Affected family members developed nephropathy almost three decades later and five heterozygous carriers developed hypertension in their forties and fifties. Thus, the clinical phenotype of our homozygous patient was more severe (earlier onset of nephropathy, cardiac and hepatic involvement) than those of heterozygotes in the same family, consistent with gene dosage effects on the phenotype of AFib amyloidosis. The follow-up of hypertensive heterozygous carriers will be helpful in the study of the pathogenesis of hypertension in AFib amyloidosis.

In systemic amyloidosis, solid organ transplantation has been used to replace failing organ function [26-29]. Isolated RTx alone has been performed for ESRF in several patients with AFib and probably remains appropriate when there is good evidence that amyloid deposition does not threaten the function of other vital organs. Gillmore et al. reported that RTx in AFib is associated with recurrence of amyloid in the graft with resultant loss of transplanted kidneys after a median of 6.7 years [3]. CLKT in a patient with amyloidotic renal failure caused by the FGA p.Glu545Val mutation was first performed in 1995 [28]. Despite liver transplantation being the only currently available curative treatment for AFib, it seems reasonable to propose it for younger and fitter patients, weighing the high risk of early perioperative death following CLKT against the elimination of the risk of recurrent amyloid disease in the allograft $[3,29]$. Transplantation in our patient aimed to replace her failing organ function, because in 1996 her amyloid type was unknown; it was 5 years later that we made a retrospective diagnosis of hereditary fibrinogen amyloidosis. Despite isolated RTx, our patient's outcome was not unfavourable compared to the results with CLKT $[3,4]$. Her apparent cardiac and hepatic AFib involvement progressed despite clinical absence of disease recurrence in the allograft. Mild proteinuria appeared 13 years after transplantation, but allograft function remained good until 4 months before the patient's death. At that time, cardiovascular symptoms were her principal problem, due to cardiac amyloidosis suggested by echocardiography. In patients with cardiac AFib involvement, combined heart-liver, heart-kidney, or heartliver-kidney transplantation could be discussed [30, 31], but, given the high risk in our 67-year-old patient, she received recommended drug treatment only. She died 16 years after renal transplantation due to severe heart failure in the context of sepsis.

\section{Conclusions}

In conclusion, correct identification of amyloidogenic protein should always be pursued, even retrospectively, because it enables the choice of the most appropriate therapy, avoids unnecessary and potentially harmful treatments, and ensures family screening. This first report of a homozygous AFibE526V (p.Glu545Val) amyloidosis expands our knowledge about the phenotype and the outcome of isolated renal transplantation and may be relevant for understanding the molecular mechanisms of dominance in hereditary amyloidosis.

\section{Conflict of Interests}

The authors declare that there is no conflict of interests regarding the publication of this paper.

\section{Authors' Contribution}

Isabel Tavares and Luísa Lobato, the first and second authors, contributed equally to this paper.

\section{Acknowledgments}

The authors thank posthumously Dr. Elísio Carvalho of the Department of Nephrology and Renal Pathology of Centro Hospitalar de São João, Porto, Portugal, for his contribution to this work. They thank Professor João Paulo Oliveira for his critical revision of the paper. This work was supported by the National Funds through the FCT, Fundação para a Ciência e Tecnologia (Portuguese National Funding Agency 
for Science, Research and Technology) in the frameworks of the PEst-OE/SAU/UI0215/2014 project, Unit for Multidisciplinary Research in Biomedicine, UMIB/ICBAS/UP.

\section{References}

[1] M. D. Benson, J. Liepnieks, T. Uemichi, G. Wheeler, and R. Correa, "Hereditary renal amyloidosis associated with a mutant fibrinogen $\alpha$-chain," Nature Genetics, vol. 3, no. 3, pp. 252-255, 1993.

[2] M. De Carvalho, R. P. Linke, F. Domingos et al., "Mutant fibrinogen $\mathrm{A}-\alpha$-chain associated with hereditary renal amyloidosis and peripheral neuropathy," Amyloid, vol. 11, no. 3, pp. 200-207, 2004.

[3] J. D. Gillmore, H. J. Lachmann, D. Rowczenio et al., "Diagnosis, pathogenesis, treatment, and prognosis of hereditary fibrinogen Aalpha-chain amyloidosis," Journal of the American Society of Nephrology, vol. 20, no. 2, pp. 444-451, 2009.

[4] A. J. Stangou, N. R. Banner, B. M. Hendry et al., "Hereditary fibrinogen a $\alpha$-chain amyloidosis: phenotypic characterization of a systemic disease and the role of liver transplantation," Blood, vol. 115, no. 15, pp. 2998-3007, 2010.

[5] G. A. Tennent, S. O. Brennan, A. J. Stangou, J. O’Grady, P. N. Hawkins, and M. B. Pepys, "Human plasma fibrinogen is synthesized in the liver," Blood, vol. 109, no. 5, pp. 1971-1974, 2007.

[6] M. M. Picken, "Fibrinogen amyloidosis: the clot thickens!," Blood, vol. 115, no. 15, pp. 2985-2986, 2010.

[7] D. M. Rowczenio, I. Noor, J. D. Gillmore et al., "Online registry for mutations in hereditary amyloidosis including nomenclature recommendations," Human Mutation, vol. 35, pp. E2403E2412, 2014.

[8] T. Uemichi, J. J. Liepnieks, and M. D. Benson, "Hereditary renal amyloidosis with a novel variant fibrinogen," The Journal of Clinical Investigation, vol. 93, no. 2, pp. 731-736, 1994.

[9] T. Uemichi, J. J. Liepnieks, F. Alexander, and M. D. Benson, "The molecular basis of renal amyloidosis in Irish-American and Polish-Canadian kindreds," QJM, vol. 89, no. 10, pp. 745750,1996

[10] M. Eriksson, S. Schönland, R. Bergner et al., “Three German fibrinogen A $\alpha$-chain amyloidosis patients with the p.Glu526Val mutation," Virchows Archiv, vol. 453, no. 1, pp. 25-31, 2008.

[11] J. R. Machado, M. V. D. Silva, P. D. M. D. M. Neves et al., "Fibrinogen A alpha-chain amyloidosis: report of the first case in Latin America," Amyloid, vol. 20, no. 1, pp. 52-55, 2013.

[12] C. P. J. Maury, J. Kere, R. Tolvanen, and A. de la Chapelle, "Homozygosity for the Asn187 gelsolin mutation in Finnishtype familial amyloidosis is associated with severe renal disease," Genomics, vol. 13, no. 3, pp. 902-903, 1992.

[13] C. P. J. Maury, "Homozygous familial amyloidosis, finnish type: demonstration of glomerular gelsolin-derived amyloid and non-amyloid tubular gelsolin," Clinical Nephrology, vol. 40, no. 1, pp. 53-56, 1993.

[14] J. Skare, H. Yazici, E. Erken et al., "Homozygosity for the met30 transthyretin gene in a Turkish kindred with familial amyloidotic polyneuropathy," Human Genetics, vol. 86, no. 1, pp. 89-90, 1990.

[15] T. Yoshinaga, M. Nakazato, S.-I. Ikeda, and A. Ohnishi, "Homozygosity for the transthyretin-Met30 gene in three Japanese siblings with type I familial amyloidotic polyneuropathy," Neurology, vol. 42, no. 10, pp. 2045-2047, 1992.
[16] M. Munar-Qués, J. M. L. Domínguez, C. Viader-Farré, P. Moreira, and M. J. M. Saraiva, "Two Spanish sibs with familial amyloidotic polyneuropathy homozygous for the V30M-TTR gene," Amyloid, vol. 8, no. 2, pp. 121-123, 2001.

[17] A. Yoshioka, Y. Yamaya, S. Saiki et al., "A case of familial amyloid polyneuropathy homozygous for the transthyretin Val30Met gene with motor-dominant sensorimotor polyneuropathy and unusual sural nerve pathological findings," Archives of Neurology, vol. 58, no. 11, pp. 1914-1918, 2001.

[18] G. Holmgren, U. Hellman, H. E. Lundgren, O. Sandgren, and O. B. Suhr, "Impact of homozygosity for an amyloidogenic transthyretin mutation on phenotype and long term outcome," Journal of Medical Genetics, vol. 42, no. 12, pp. 953-956, 2005.

[19] K. Tojo, Y. Sekijima, K. Machida, A. Tsuchiya, M. Yazaki, and S.I. Ikeda, "Amyloidogenic transthyretin Val30Met homozygote showing unusually early-onset familial amyloid polyneuropathy," Muscle and Nerve, vol. 37, no. 6, pp. 796-803, 2008.

[20] D. R. Jacobson, P. D. Gorevic, G. H. Sack, and R. L. Malamet, "Homozygous transthyretin His 58 associated with unusually aggressive familial amyloidotic polyneuropathy," The Journal of Rheumatology, vol. 20, p. 178, 1993.

[21] A. Ferlini, F. Salvi, A. Uncini et al., "Homozygosity and heterozygosity for the transthyretin Leu64 mutation: clinical, biochemical and molecular findings," Clinical Genetics, vol. 49, no. 1, pp. 10-14, 1996.

[22] I. M. Hamour, H. J. Lachmann, H. J. B. Goodman et al., "Heart transplantation for homozygous familial transthyretin (TTR) V122I cardiac amyloidosis," The American Journal of Transplantation, vol. 8, no. 5, pp. 1056-1059, 2008.

[23] H. V. Reddi, S. Jenkins, J. Theis et al., "Homozygosity for the V122I mutation in transthyretin is associated with earlier onset of cardiac amyloidosis in the african american population in the seventh decade of life," Journal of Molecular Diagnostics, vol. 16, no. 1, pp. 68-74, 2014.

[24] P. M. P. Costa, Amiloidoses transtirretínicas, da biopatologia à terapêutica [Ph.D. dissertation], Porto University, 1993.

[25] I. Tavares, R. Vaz, L. Moreira et al., "Renal amyloidosis: classification of 102 consecutive cases," Portuguese Journal of Nephrology and Hypertension, vol. 28, no. 3, pp. 201-209, 2014.

[26] C. Mousson, B. Heyd, E. Justrabo et al., "Successful hepatorenal transplantation in hereditary amyloidosis caused by a frameshift mutation in fibrinogen A $\alpha$-chain gene," American Journal of Transplantation, vol. 6, no. 3, pp. 632-635, 2006.

[27] S. Y. Tan, M. B. Pepys, and P. N. Hawkins, "Treatment of amyloidosis," American Journal of Kidney Diseases, vol. 26, no. 2, pp. 267-285, 1995.

[28] J. D. Gillmore, D. R. Booth, M. Rela et al., "Curative hepatorenal transplantation in systemic amyloidosis caused by the Glu526Val fibrinogen $\alpha$-chain variant in an English family," QJM, vol. 93, no. 5, pp. 269-275, 2000.

[29] J. H. Pinney, H. J. Lachmann, P. T. Sattianayagam et al., "Renal transplantation in systemic amyloidosis-importance of amyloid fibril type and precursor protein abundance," The American Journal of Transplantation, vol. 13, no. 2, pp. 433-441, 2013.

[30] E. Raichlin, R. C. Daly, C. B. Rosen et al., "Combined heart and liver transplantation: a single-center experience," Transplantation, vol. 88, no. 2, pp. 219-225, 2009.

[31] T. Legris, L. Daniel, and V. Moal, "Delayed diagnosis of fibrinogen $\mathrm{A} \alpha$-chain amyloidosis after dual heart-kidney transplantation," Transplant International, vol. 26, no. 1, pp. el-e3, 2013. 


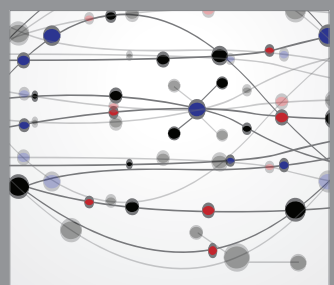

The Scientific World Journal
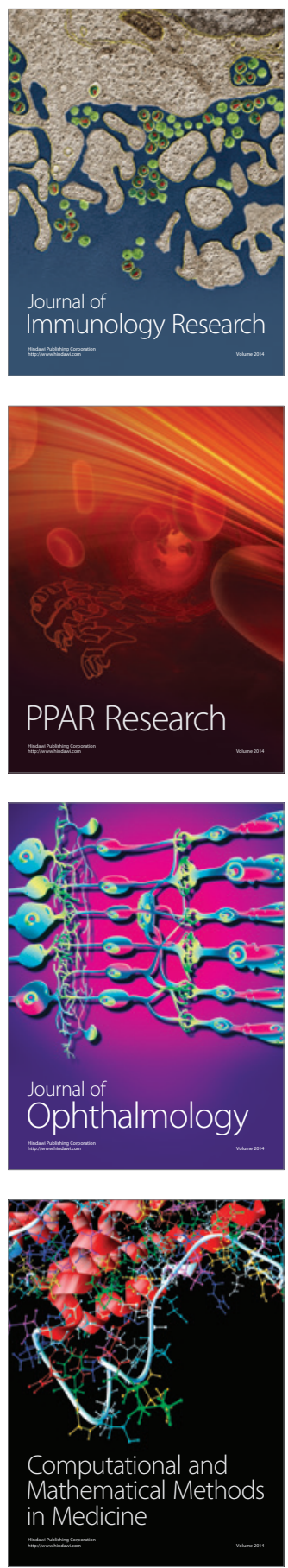

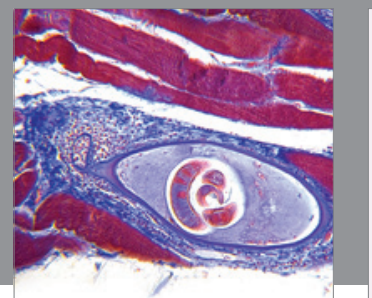

Gastroenterology

Research and Practice
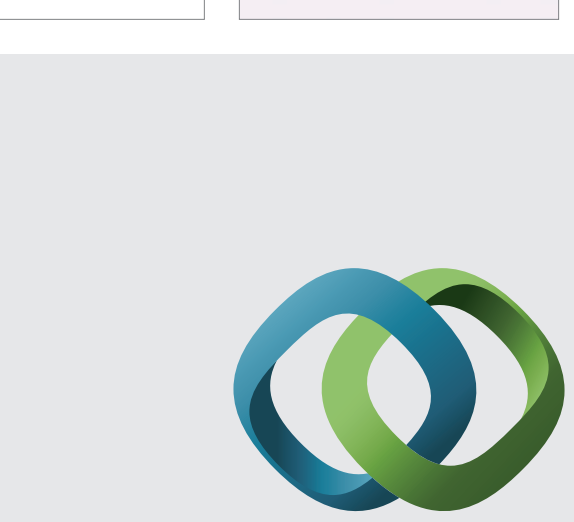

\section{Hindawi}

Submit your manuscripts at

http://www.hindawi.com
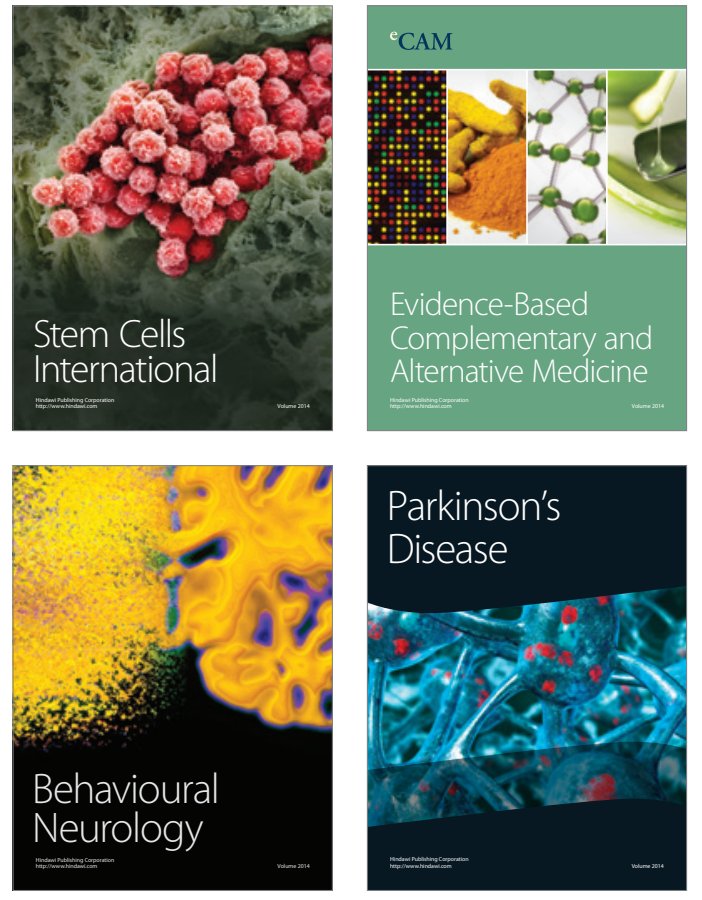
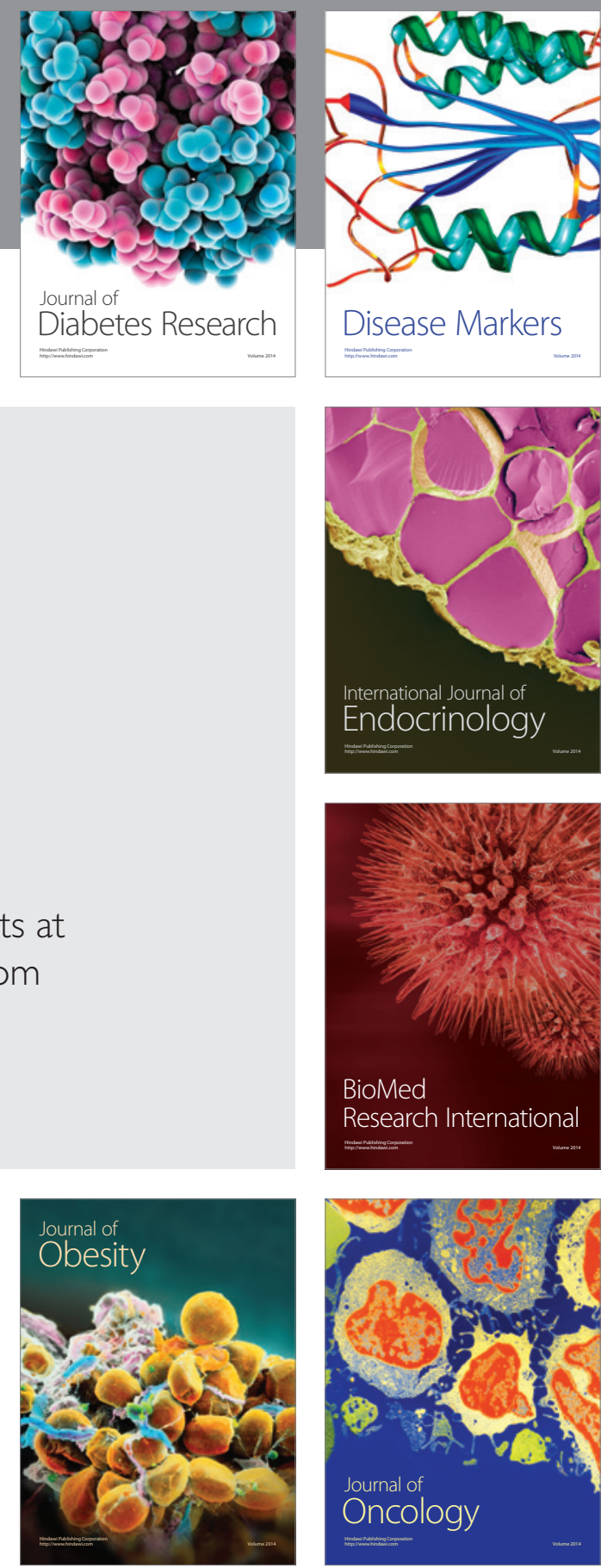

Disease Markers
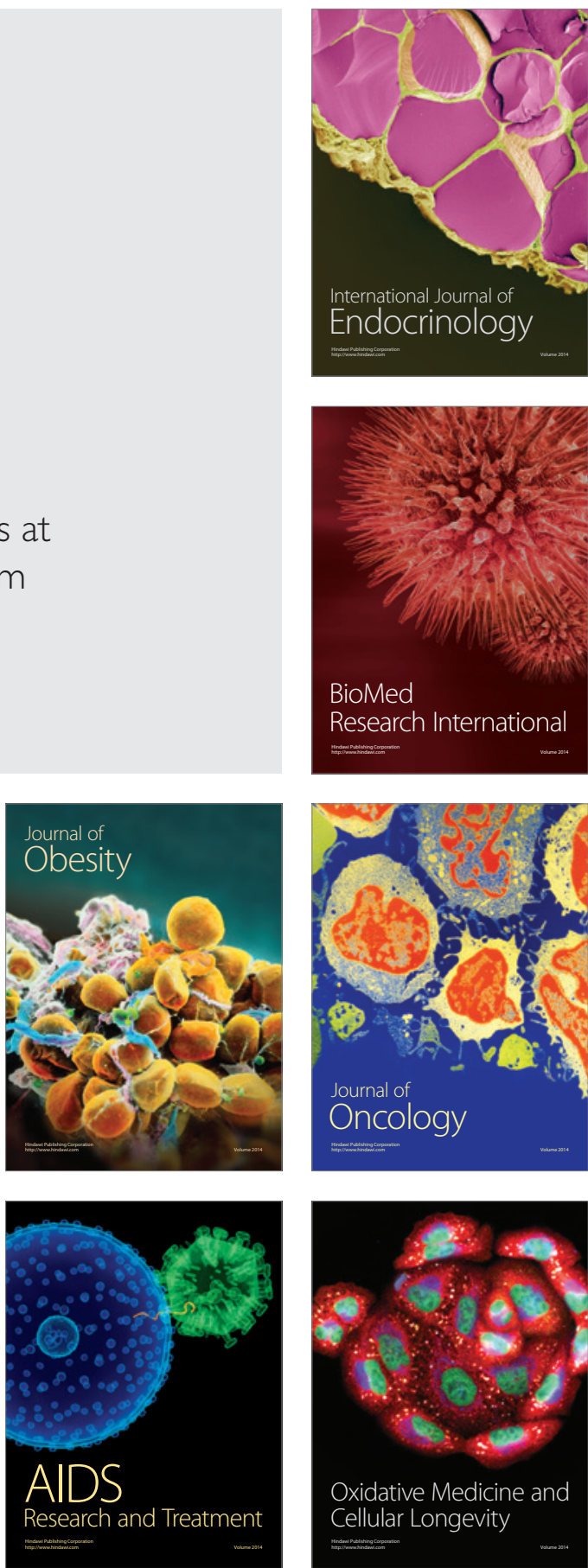